\title{
Evaluation and outcome of aphasia in patients with severe closed head trauma
}

\author{
INGER VIBEKE THOMSEN ${ }^{1}$ \\ From the Department of Neurology, Bispebjerg Hospital, Copenhagen \\ and the Hospital for Physical Medicine, Hornbaek, Denmark
}

SYNOPSIS In this study long-term observation of 12 patients with aphasia secondary to severe closed head trauma took place. The most frequent symptoms were amnestic aphasia and verbal paraphasia. Only one patient with a constant slow wave EEG focus in the dominant hemisphere had severe receptive symptoms. In all other patients the aphasia recovered rather well, though not totally, but the presence and degree of concomitant neuropsychological disorders were most important for the final outcome.

The relationship between head injury and loss of speech has been known for thousands of years as seen in the reports of the Egyptian surgeons between $3000-2500$ BC (Breasted, 1930). Descriptions of such cases have, however, been few until the time of the first and second world wars. During these periods a great amount of literature on post-traumatic aphasia secondary to penetrating wounds was published. In contrast with this abundant literature, the paucity of works on post-traumatic aphasia in peace time is striking, and this is especially true in cases of aphasia secondary to closed head injuries.

The purpose of this study has been to evaluate the types of aphasia that occur after severe concussion and to study the outcome of the language disturbances. In contrast with an investigation by Heilman et al. (1971), in which the period of observation was rather short, systematic followup of the patients in this series has been carried out for a long time.

\section{METHODS}

SUBJECTS In a series of 50 head patients with head injuries the only criterion of selection was the severity of the trauma, all patients being deeply unconscious for more than 24 hours. Twenty-four of the patients had focal lesions and 26 had closed head trauma. Twelve of the last-mentioned patients, five

1 Address for reprints: Solvænger 32, 2960 Rungsted Kyst, Denmark. (Accepted 11 March 1975.) men and seven women with a mean age of 25.5 years, who had symptoms of aphasia when seen by the speech pathologist four months on average after the injury, are the subjects of this study. All but one were victims of traffic accidents. The patients were unconscious at the scene of accident and on admission to hospital and remained so for days or weeks. One patient reacted to speech two weeks after the trauma; four patients reacted three to four weeks after the accident, and the remaining seven patients did not react until five to eight weeks after the injury.

The types of cerebral lesions are presented in Table 1.

At the time of the primary examination all but three of the patients had severe motor disabilities. One patient had tetraplegia, one quadriplegia, two bilateral spasticity, and five had hemiparesis (one left and four right). In addition, four patients had a supranuclear seventh cranial nerve lesion. Ten patients were right-handed, and the patient with left

TABLE 1

TYPES OF CEREBRAL LESIONS IN 12 PATIENTS WITH CLOSED HEAD TRAUMA

\begin{tabular}{lc}
\hline Types of lesion & $\begin{array}{c}\text { Patients } \\
\text { (no.) }\end{array}$ \\
\hline Brain concussion* & 7 \\
Brain concussion and brainstem lesion & 3 \\
Brain concussion and hypoxia & 2 \\
\hline
\end{tabular}

* Contusion in Scandinavian terminology. 
hemiparesis was also right-handed; two were lefthanded. One of the last mentioned was the patient with quadriplegia, the other had a right nuclear seventh cranial nerve lesion and diminished strength on the left side.

The follow-up examination took place from 12 to 50 months (on average 33 months) after injury. The interval between the trauma and the reexamination was less than two years in four patients and more than two years in eight patients. The patients were readmitted to hospital and seen by a neurologist, a clinical psychologist, and the speech pathologist, who also visited the patients in their homes. Nine patients stayed with their families, one lived on her own, one was a patient in a nursing home, and one was in a psychiatric hospital. Only three patients had severe motor symptoms; they were the patients with quadriplegia and tetraplegia respectively, and one patient with hemiparesis. None had post-traumatic epilepsy.

The electroencephalogram (EEG) was normal in one patient. Slow waves were registered over both temporal lobes in four patients, over the dominant temporal lobe in two patients, all over the hemisphere in three patients, and over both hemispheres in two patients.

On the Wechsler Adult Intelligence Scale (WAIS) the performance mean score was 83 , ranging from 97 to 68 .

Two patients were employed at the time of the follow-up. One of these had returned to her previous work as a clerk but had difficulties in managing. The other, who was a student at a training college at the time of the accident, now worked as a cleaner. One patient worked in a sheltered workshop. The remaining nine patients had no work.

TECHNIQUES Testing of aphasia was seldom possible at the time of the first examination, and the primary results are therefore based on observation during the first two or three weeks (Table 2, A). In most cases, observation took place over periods of months or years.

At the time of the follow-up, tests were made for aphasia. The author's test of aphasia included investigation of oral praxis, tests of comprehension of spoken language and silent reading, repetition of words and sentences, naming, description of a series of thematic pictures, synonyms, antonyms and metaphors, spontaneous writing and writing to dictation, right-left orientation, finger recognition, and simple calculation. If the patient was not able to do silent reading, basic reading - that is, matching objects with the corresponding words-was tested. Spontaneous speech was evaluated. Orientation in time and space was tested, and the patient was given some questions concerning simple general information. The test was tape recorded. Verbal and non-verbal learning ability were examined by different tests.

\section{RESULTS}

According to the results in the test of aphasia at the follow-up examination, four of the 12 patients had no symptoms of aphasia. A linguistic analysis of spontaneous speech revealed, however, aphasic traits - as many immediate repetitions of words and false starts of sentences-in one patient. The three other patients had impaired verbal learning with errors similar to those of the aphasic patients. Of the eight patients with symptoms of aphasia in the clinical test of aphasia one only (case 1) had severe disorders of communication.

The aphasic symptoms and other defects of higher cortical functions at the time of the first examination (A) and at the follow-up (B) are presented in Table 2.

\section{TABLE 2}

DEFECTS OF HIGHER CORTICAL FUNCTIONS AT FIRST EXAMINATION (A) AND AT FOLLOW-UP (B) IN 12 PATIENTS WITH CLOSED HEAD TRAUMA

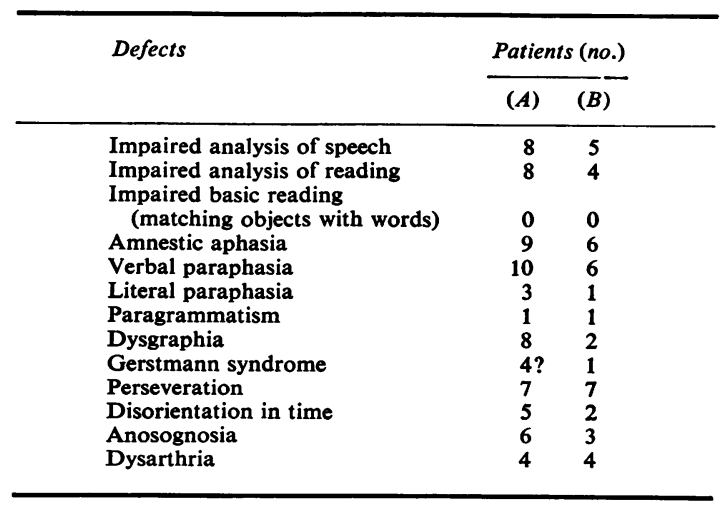

It is seen in Table 2 (B) that five patients had impaired analysis of speech at the follow-up. The difficulty was severe in only one patient (case 1) with semantic errors - that is, confusion between words associated in meaning - as well as impaired phoneme discrimination. In three patients, a few semantic errors were found in the test of 
identification, but the main problem was, in two of the cases, the bradyphrenia, manifesting itself in slow reactions and demands of repetition and simplification of questions. One patient made no mistakes in the tests of auditory comprehension, but in conversation she sometimes failed to recognize low-frequency words-for instance, foreign ones-which had been familiar to her before the accident. In the tests of synonyms and antonyms she often repeated the stimulus words several times, before she was able to understand the meaning. Four patients had impaired analysis of reading at the follow-up, but no patient had at any time a total alexia - that is, impaired matching of objects with words. Table 2 also shows that amnestic aphasia and verbal paraphasia were present in nearly all patients at the first examination, and in the greater part of the patients with aphasia at the follow-up. The amnestic aphasia revealed itself in a slow rate of speaking, hesitation, periphrases, and repetition of words or fragments of sentences. The symptom was observed in spontaneous speech as well as in some of the subtests, especially naming, description of a series of thematic pictures, and in the tests of antonyms, synonyms, and metaphors. The verbal paraphasia was generally of the association type and was seldom noticed by the patients themselves. One patient (case 3), whom the clinical psychologist described as psychotic, had very peculiar and artificial paraphasia. Literal paraphasia was, at the first examination, present in three patients, of whom two were left-handed and one right-handed. At the follow-up, the symptom remained in the patient last mentioned. It is also seen in Table 2 that none of the four patients with dysarthria and none of the seven patients with perseveration made a full recovery.

As mentioned before, four of the 12 patients in this study had no symptoms of aphasia according to the results in the test at the follow-up. They were two right-handed patients and the two left-handed ones. One of the last mentioned had premorbid dyslexia and agraphia. After the trauma, the dyslexia became very severe and there was mild literal paraphasia. At follow-up, speech was normal, and the reading ability was judged to be at the same level as before the accident. The other left-handed patient had posttraumatic literal paraphasia, impaired spelling, and severe, predominantly cerebellar, dysarthria. At follow-up only the dysarthria remained. The two right-handed patients recovered from amnestic aphasia and mild verbal paraphasia.

The verbal and non-verbal learning was severely impaired in the patients who were aphasic at follow-up.

The following three cases may give an impression of the variety of language difficulties and concomitant neuropsychological disorders.

\section{CASE REPORTS}

CASE 1 (F.H.H. 563/67) A 20 year old, righthanded female, a student at a training college, was involved in a traffic accident. On admission to hospital the patient was comatose. There was a comminuted fracture of the base of the skull, and the patient developed severe cerebral oedema. The patient reacted to speech two weeks after injury, but the unconsciousness was replaced by a confusional state with amnesia and confabulation alternating with periods of excitement and hypersexuality. Ten weeks after the injury the EEG showed $2-4 \mathrm{~Hz}$ waves in the left parieto-occipital region. At examination six months after the trauma, the patient was not orientated in time. Analysis of speech and reading was impaired, and there was verbal paraphasia. The patient was euphoric. There was no paresis, but mild cerebellar symptoms and right astereognosis were observed. These symptoms remained at the follow-up 40 months after the injury, and the EEG repeated the findings of the first examination. Auditory comprehension was much below normal with impaired phoneme discrimination and semantic errors. There was dyslexia, rather severe amnestic aphasia and some verbal paraphasia, mild dysgraphia, and no dyscalculia. The patient complained bitterly of her total loss of contact. Intellectual impairment was mild (WAIS: 97), but there was a marked change in personality. The patient, whose premorbid life had been quite normal, now walked the streets.

CASE 2 (F.H.H. 7549/66) A 20 year old righthanded male, an unskilled labourer, sustained a severe brain concussion with symptoms of brainstem damage. Slow waves down to $1.0 \mathrm{~Hz}$ were present in the EEG over both hemispheres some days after the trauma. There was no reaction to speech until eight weeks after the accident. At the first examination five months after the trauma, the patient had a mild right hemiparesis, symptoms from cerebellum and a right seventh cranial nerve lesion. There was disorientation in time and no sense of time. Auditory 
comprehension was severely impaired, reading also, but the patient was able to match objects with words. Spontaneous speech was nothing but single words expressing wants (food, stools, etc.). On naming, verbal paraphasia and perseveration were severe. There was suspicion of a Gerstmann syndrome. The patient was restless, his laughter was inappropriate, and he had a total anosognosia. At the time of the follow-up 40 months after injury the patient worked in a sheltered workshop. The motor symptoms remained, but in mild degree. The EEG was abnormal over the left hemisphere. The patient was orientated in time, but was not able to answer any questions concerning general information. In conversation and in tests the immediate answer often was ' $I$ do not know'. The patient had a few semantic errors in tests of auditory comprehension, but the main problem was bradyphrenia. Silent reading was not possible, but the patient could read an easy anecdote aloud. Spontaneous speech was slow, and the patient talked very little. He spoke with pauses, repetitions and aposiopesis - for example, 'I really am ... really I am ... I cannot say how I am . . . I really am very well when I work ... but when I do not work ... The voice was monotonous and childlike, and there was mild dysarthria. The choice of words was sometimes like that of a child of 3 to 4 years old. There was no Gerstmann syndrome, and the patient was able to write some sentences from dictation and to do simple calculation on paper. The WAIS was 68 .

CASE 3 (B.B.H./N. 536/69) A 25 year old righthanded male, an engineer, sustained a severe brain concussion with oedema. He was deeply unconscious for about eight weeks. There was a left hemiparesis and a left hemianopia. The EEG showed 1-3 Hz waves over both hemispheres. When first seen by the speech pathologist eight months after injury, the patient stayed in a psychiatric hospital. The motor symptoms were then mild. There was disorientation in time and no sense of time. Auditory comprehension was normal, but there was a $50 \%$ error in the test of silent reading. Reading aloud did not present much difficulty. Amnestic aphasia, verbal paraphasia, and perseveration were frequent. Literal dysgraphia, errors and defiguration were present in spontaneous writing and to some degree in copying. There was severe dyscalculia, mental and upon paper, and constructional apraxia. Finger identification was intact. The patient was seen once or twice a week during the following year. At the follow-up 28 months after the accident, the patient was still in the psychiatric hospital and was described as psychotic (schizophrenic type). There was no indication of premorbid schizophrenic traits. The EEG showed slow waves in both temporal regions, and a pneumo- encephalogram showed severe symmetrical enlargement of the lateral ventricles. There was disorientation in time and no sense of time. Auditory comprehension was normal, silent reading too, but the patient read aloud to himself. Speech was elaborate with frequent amnestic intervals, many repetitions, and diversions by irrelevant associations. Aposiopesis as well as false starts of sentences were often present. There was paragrammatism with displacements of adjectives and verbal paraphasia, often of a peculiar type. The patient, for example, said about Autumn, 'The trees are turned pale'. He created neologisms by combining words as, 'A seastory ... no yes a fairy ... . a tourstory ... . or an account of a journey'. Anger, irritation, and regression were reflected in the voice, and the changes were very sudden. There was no dysgraphia and no dyscalculia.

\section{DISCUSSION}

Amnestic aphasia and verbal paraphasia were the most frequent symptoms in this investigation. This is in agreement with the results of a study of aphasics with closed head trauma by Heilman et al. (1971). Central dysfunctions are closely associated with thinking, and it was characteristic of the patients in this study that tests on a rather high level, such as synonyms, antonyms, and metaphors, created great difficulty. Description of a series of thematic pictures, especially the finding of a short and precise headline, was extremely difficult. Verbal paraphasia was often observed in spontaneous speech and in the tests. Errors of the association type were the most common ones, as described by Schuell and Jenkins (1961). The fact that the patients seldom paid attention to their verbal paraphasia indicates that this aphasic element is more closely associated with receptive than expressive disorders (Fog and Hermann, 1961). The artificial verbal paraphasia in the psychotic patient (case 3 ) is of interest because the peculiar choice and combination of words, as well as other features in the language and voice, reveal the psychiatric components. The so-called non-aphasic misnaming, where patients with diffuse involvement of the nervous system substitute names of objects related to their illness for correct names (Geschwind, 1967), was not observed in any patient in this investigation. Three patients had literal paraphasia. The symptom was present in one right-handed patient only. It is no accident that the two left-handed patients had literal 
paraphasia, since expressive dysfunctions occur significantly more frequently in left-handed individuals than in right-handed ones (Hécaen and Angelergues, 1962). Several patients had impaired analysis of reading, but none of them had, at any time, a total alexia, as they were able to match objects with words. This function is better preserved in aphasics than identification of letters (Thomsen, 1968) and can therefore be considered as basic reading. In this series, no recovery was seen as regards perseveration. The disorder, which has been described as the most common symptom in patients with organic brain involvement (Eisenson, 1954), was seldom noticed by the patients themselves and so must, like the verbal paraphasia, be looked upon as an afferent dysfunction (Schuell, 1950). The outcome of dysarthria was poor. Similar results were registered in dysarthric non-aphasics with diffuse cerebral damage in the author's basic material. The articulatory defects improved in some cases with treatment, but monotony persisted.

All patients in this study had severe diffuse neuronal damage, but with one exception (case 1) it is not possible to know if any regions of the brain had been particularly exposed to damage. It may be of some interest that the EEG of half the patients showed slow waves over the dominant temporal lobe or over both temporal lobes. Temporal contre-coup lesions are common in severe head injuries (Courville, 1942), and temporal lobe damage bears a special relationship to aphasia and, to some extent, to psychiatric disability (Lishman, 1966).

The prognosis of post-traumatic aphasia has been described as rather good, at any rate better than in aphasia secondary to cerebrovascular diseases (Alajouanine et al., 1957). The results in this study are in agreement with this finding where patients with closed head injury are concerned. That aphasia in left-handed patients is often transitory (Subirana, 1958; Zangwill, 1960; Hécaen and Angelergues, 1962) can also be seen in this series. It must, however, be remembered that no patient in this investigation had a normal language function, since linguistic analysis and tests of verbal learning revealed aphasic traits. Furthermore, it is not possible in this series to consider aphasia as an isolated disorder, since impaired language was part of a neuropsycho- logical syndrome in which residual defects of general memory often dominated. In very severe cases-for example, case 2, where bradyphrenia, poverty of speech, perseveration, aposiopesis, and total impairment of silent reading were prominent features-the language function could be described as dyslogia (Critchley, 1964).

It is no mere coincidence that the afferent symptoms were most pronounced in a patient (case 1) with a constant slow wave EEG focus in the dominant parieto-occipital region, since the relationship between this lesion and defects of comprehension is well known (Hécaen and Angelergues, 1964). The persistent impairment of language in the patient mentioned corresponds with the findings in head injury patients with verified focal lesions, in whom full recovery is seldom seen (Thomsen, to be published).

From the results in this investigation it can thus be concluded that aphasia secondary to severe closed head injury tends to recover rather well, but not totally, and that the presence and degree of concomitant neuropsychological disorders are most important for prognosis.

\section{REFERENCES}

Alajouanine, T., Castaigne, P., Lhermitte, F., Escourolle, R., and de Ribaucourt, B. (1957). Etude de 43 cas d'aphasie post-traumatique. Encéphale, 46, 1-45.

Breasted, J. H. (1930). The Edwin Smith Surgical Papyrus, vol. 1. University of Chicago Press: Chicago.

Courville, C. B. (1942). Coup-contrecoup mechanism of cranio-cerebral injuries. Archives of Surgery, 45, 19-43.

Critchley, M. (1964). The neurology of psychotic speech. British Journal of Psychiatry, 110, 353-364.

Eisenson, J. (1954). Examining for Aphasia. New York Psychological Corporation: New York.

Fog, M., and Hermann, K. (1961). Afatiske Sprogforstyrrelser. Munksgaard: København.

Geschwind, N. (1967). The varieties of naming errors. Cortex, 3, 97-112.

Hécaen, H., and Angelergues, R. (1962). L'aphasie, l'apraxie, l'agnosie chez les gauchers. Revue Neurologique, 106, 510515.

Hécaen, H., and Angelergues, R. (1964). Localization of symptoms in aphasia. In Disorders of Communication. Edited by A. V. S. de Reuck and M. O'Connor. Churchill: London.

Heilman, K. M., Safran, A., and Geschwind, N. (1971). Closed head trauma and aphasia. Journal of Neurology, Neurosurgery, and Psychiatry, 34, 265-269.

Lishman, W. A. (1966). Psychiatric disability after head injury: the significance of brain damage. Proceedings of the Royal Society of Medicine, 59, 261-266.

Schuell, H. (1950). Paraphasia and paralexia. The Journal of Speech and Hearing Disorders, 15, 291-306. 
Schuell, H., and Jenkins, J. J. (1961). Reduction of vocabulary in aphasia. Brain, 84, 243-261.

Subirana, A. (1958). The prognosis in aphasia in relation to the factor of cerebral dominance and handedness. Brain, 81, 415-425.
Thomsen, I. V. (1968). Undersøgelse, behandling og behandlingsresultater hos patienter med erhvervet afasi. Ugeskrift for Laeger, 130, 1537-1541.

Zangwill, O. L. (1960). Cerebral Dominance and its Relation to Psychological Function. Thomas: Springfield, Ill. 